\title{
TLR4 promoter rs1927914 variant contributes to the susceptibility of esophageal squamous cell carcinoma in the Chinese population
}

\author{
Jiaying Li ${ }^{1,2}$, Hongjiao Wu ${ }^{1}$, Hui Gao ${ }^{1}$, Ruihuan Kou ${ }^{3}$, Yuning Xie ${ }^{1,2}$, Zhi Zhang $^{3}$, Xuemei Zhang ${ }^{\text {Corresp. } 1,2}$ \\ ${ }^{1}$ School of Public Health, North China University of Science and Technology, Tangshan, China \\ 2 College of Life Science, North China University of Science and Technology, Tangshan, China \\ 3 Affliated Tangshan Gongren Hospital, North China University of Science and Technology, Tangshan, China \\ Corresponding Author: Xuemei Zhang \\ Email address: jyxuemei@gmail.com
}

Background. Toll-like receptor 4 (TLR4), as a key regulator of both innate and acquired immunity has been linked with the development of various cancers, including esophageal cancer. This study aims to analyze the association of potential functional genetic polymorphisms in TLR4 with the risk of esophageal cancer.

Methods. This case-control study involved in 480 ESCC patients and 480 health controls. Polymerase chain reaction-restriction fragment length polymorphism (PCR-RFLP) was used to genotype TLR4 rs1927914 polymorphism. Taqman probe method was used to determine the genotypes of TLR4 rs11536891 and rs7873784 variants. The relationship between TLR4 genetic variation and ESCC risk was analyzed by Logistic regression model by calculating the odds ratio $(O R)$ and $95 \%$ confidence interval $(95 \% \mathrm{Cl})$.

Results. Compared with TLR4 rs1927914AA genotype carriers, GG carriers had a lower ESCC risk $(O R=$ $0.59,95 \% \mathrm{Cl}=0.38-0.93, P=0.023$ ). Stratification analysis by age showed that TLR4 rs1927914GG could affect the risk of ESCC in elderly people $(O R=0.59,95 \% \mathrm{Cl}=0.36-0.97)$. Smoking stratification analysis indicated that rs $1927914 \mathrm{GG}$ carriers were related to ESCC susceptibility among non-smokers $(O R=$ $0.36,95 \% \mathrm{Cl}=0.18-0.73$ ). Dual luciferase reporter assay suggested that rs $1927914 \mathrm{G}$-containing TLR4 promoter displayed a 1.76-fold higher luciferase activity than rs1927914A-containing counterpart in KYSE30 cells. Electrophoretic mobility shift assay (EMSA) showed the KYSE cell nuclear extract was able to bind the probe with rs $1927914 \mathrm{G}$ allele and this DNA-protein interaction could be eliminated by competition assays with unlabeled rs $1927914 \mathrm{G}$ probe, which indicating that the binding is sequencespecific. Our results also showed that TLR4 rs7873784 (G>C) and rs11536891 (T>C) conformed to complete genetic linkage. The genotype distributions of TLR4 rs11536891 variant among ESCC patients and normal controls have no statistical significance.

Conclusion. TLR4 rs1927914 variant contribute to the ESCC risk by effecting the promoter activity. 
1 TLR4 promoter rs1927914 variant contributes to the susceptibility of esophageal squamous 2 cell carcinoma in the Chinese population

4 Jiaying $\mathrm{Li}^{1,2}$, Hongjiao $\mathrm{Wu}^{1}$, Hui $\mathrm{Gao}^{1}$, Ruihuan $\mathrm{Kou}^{3}$, Yuning Xie ${ }^{1,2}$, Zhi Zhang ${ }^{3}$, Xuemei 5 Zhang ${ }^{1,2, *}$

$7{ }^{1}$ School of Public Health, North China University of Science and Technology, Tangshan, Hebei, 8 China

$9{ }^{2}$ College of Life Science, North China University of Science and Technology, Tangshan, Hebei, 10 China

$11{ }^{3}$ Affliated Tangshan Gongren Hospital, North China University of Science and Technology, 12 Tangshan, Hebei, China

$14 *$ Corresponding Author:

15 Xuemei Zhang

1621 Bohai Road, Caofeidian Xincheng, Tangshan/Hebei, 063009, China

17 Email address: jyxuemei@gmail.com 


\section{Abstract}

Background. Toll-like receptor 4 (TLR4), as a key regulator of both innate and acquired immunity has been linked with the development of various cancers, including esophageal cancer. This study aims to analyze the association of potential functional genetic polymorphisms in TLR4 with the risk of esophageal cancer.

Methods. This case-control study involved in 480 ESCC patients and 480 health controls. Polymerase chain reaction-restriction fragment length polymorphism (PCR-RFLP) was used to genotype TLR4 rs1927914 polymorphism. Taqman probe method was used to determine the genotypes of TLR4 rs11536891 and rs7873784 variants. The relationship between TLR4 genetic variation and ESCC risk was analyzed by Logistic regression model by calculating the odds ratio $(O R)$ and $95 \%$ confidence interval $(95 \% C I)$.

Results. Compared with TLR4 rs1927914AA genotype carriers, GG carriers had a lower ESCC risk $(O R=0.59,95 \% C I=0.38-0.93, P=0.023)$. Stratification analysis by age showed that TLR4 rs $1927914 \mathrm{GG}$ could affect the risk of ESCC in elderly people $(O R=0.59,95 \% C I=0.36-0.97)$. Smoking stratification analysis indicated that rs1927914 GG carriers were related to ESCC susceptibility among non-smokers $(O R=0.36,95 \% C I=0.18-0.73)$. Dual luciferase reporter assay suggested that rs1927914G-containing TLR4 promoter displayed a 1.76-fold higher luciferase activity than rs1927914A-containing counterpart in KYSE30 cells. Electrophoretic mobility shift assay (EMSA) showed the KYSE cell nuclear extract was able to bind the probe with rs1927914 G allele and this DNA-protein interaction could be eliminated by competition assays with unlabeled rs1927914 G probe, which indicating that the binding is sequence-specific. Our results also showed that TLR4 $\operatorname{rs} 7873784(\mathrm{G}>\mathrm{C})$ and $\operatorname{rs} 11536891(\mathrm{~T}>\mathrm{C})$ conformed to complete genetic linkage. The genotype distributions of TLR4 rs11536891 variant among ESCC patients and normal controls have no statistical significance.

Conclusion. TLR4 rs1927914 variant contribute to the ESCC risk by effecting the promoter activity. 


\section{Introduction}

Esophageal cancer, as the sixth leading cause of cancer death, is one of the most common malignant tumors worldwide (Bray et al. 2018). Esophageal cancer contains two common histological types: esophageal adenocarcinoma (EAC) and esophageal squamous cell carcinoma (ESCC). There are clear differences between EAC and ESCC that affect their distribution and incidence in the world (Domper Arnal et al. 2015; Yang et al. 2016). In China, most of the cases of esophageal cancer are squamous cell cancer (Lin et al. 2013). ESCC is caused by environmental and genetic factors. Epidemiological studies have reported that tobacco smoking, alcohol drinking, ingesting hot substances and so on played a role in the development of ESCC (Yu et al. 2018a). However, not all individuals who have been exposed to these hazards eventually get ESCC. In recent years, genetic polymorphisms have been reported to impact the development of esophageal cancer (Hiyama et al. 2007; Yue et al. 2017). 
antigen-derived cells such as dendritic cells, and then activate the tumor-specific $\mathrm{T}$ cells immune which involving in the development of tumors (Kaczanowska et al. 2013; Pham et al. 2010). TLR4 can not only recognize extracellular antigens, but also respond to intracellular injury related factors (Jacobsen et al. 1991; Rocha et al. 2016). Study showed that TLR4 induced by LPS promoted the secretion of immunosuppressive cytokines which promoted the proliferation of lung cancer and ESCC cells (He et al. 2007; Zu et al. 2017). TLR4 also involved in the antitumor T-cell immune response by induced by danger-associated molecular patterns (DAMPs) (Fang et al. 2014). Studies have shown that TLR4 is overexpressed in a variety of malignant tumors and associated with poor prognosis in cancer patients (Li et al. 2017; Pandey et al. 2018; Sheyhidin et al. 2011; Wang et al. 2017; Zhao et al. 2019). TLR4 has been identified as a potential drug target for the immuno-therapeutics in various cancers (Shetab Boushehri \& Lamprecht 2018).

In view of the important role of TLR4 in tumors, we screened out the potential functional SNPs in TLR4 using bioinformatic methods and then performed a case-control study in Chinese population to determine whether they were correlated with the occurrence of ESCC.

\section{Materials and methods}

\section{Study subjects}

In this study, 480 ESCC patients and 480 cancer-free controls were included. Cases were recruited from Apr 2008 to Dec 2012 in Affiliated Tangshan Gongren Hospital and Tangshan Renmin Hospital of North China University of Science and Technology (Tangshan, China). Inclusion criteria: all patients were diagnosed as primary ESCC by histopathology; all specimens were genetically unrelated Han Chinese; none of the patients had received radiotherapy or chemotherapy. 480 healthy individuals were randomly recruited from the same region and matched with cases on age and sex. All participants signed the written informed consent. Institutional Review Board of North China University of Science and Technology had approved the research (12-002). 


\section{TLR4 SNPs selection}

106

107

108

109

110

111

112

113

114

115

116

117

118

119

120

121

122

123

124

125

126

127

128

In this study, we predicted the possible functional SNPs in the regulatory region of TLR4. All included SNPs located in the promoter region or the $3^{\prime}$ untranslated region with $M A F \geq 0.05$. For SNPs in the promoter region of TLR4, transcription factor binding capability was predicted by TRANSFAC program (Wingender et al. 1996). For the SNPs located in the 3' untranslated region, microRNA binding ability was predicted using SNPinfo Web Server (Xu \& Taylor 2009). Finally, TLR4 rs1927914 in the promoter region and rs11536891 and rs7873784 in the $3^{\prime}$ untranslated region were selected for further genotyping (Figure 1A).

\section{Genotype of selected TLR4 polymorphisms}

Each subject donated $2 \mathrm{~mL}$ of peripheral blood. DNA was extracted using the blood DNA kit provided by TIANGEN Biotech (Beijing). TLR4 rs1927914 genotyping was performed by the Polymerase chain reaction-restriction fragment length polymorphism (PCR-RFLP). The target DNA fragment was amplified by PCR using the forward primer 5'TGACATGGAAAATGGAGAGATAGAGG-3’ and reverse primer 5'GGACTATGATGGAGATTGAAAATGTGG-3'. PCR was performed using a $6 \mu 1$ reaction system containing $0.05 \mu \mathrm{M}$ each primer, 10ng DNA, and 2 x Es Taq MasterMix (CWBIO, Beijing, China). PCR procedure was 3 minutes at $95^{\circ} \mathrm{C}$, followed by 32 cycles $\left(30 \mathrm{~s}\right.$ at $95^{\circ} \mathrm{C}, 30 \mathrm{~s}$ at $56.5^{\circ} \mathrm{C}$ and $34 \mathrm{~s}$ at $72^{\circ} \mathrm{C}$ ) and 5 minutes at $72^{\circ} \mathrm{C}$ for final extension. TLR4 PCR products were cut by Nsi $I$ and verified with 3\% agarose gel. TLR4 rs11536891 and rs7873784 variants were genotyped by SNP genotyping assays (C_31784036_10 and C_29292008_10) (Thermo Fisher Scientific, Waltham, USA). TaqMan SNP assay includes two allele-specific TaqMan MGB probes and a PCR primer pair that uniquely amplify the region flanking of SNP. The MGB probes do not fluoresce because of the non-fluorescent quencher (NFQ) at the 3 ' end of the 
129 Taqman probe. Two allele-specific probes contain different reporter dyes (FAM and VIC)

130 specifically hybridize to the allele specific sequence. The 5' nuclease activity of AmpliTaq Gold

131 DNA polymerase in TaqMan Genotyping Master Mix (Thermo Fisher Scientific, Waltham,

132 USA) can only cleave the hybridized probes. This will separate the reporter dye from the

133 quencher and allow fluorescence emission and be detected.

134

135

136

137

138

139

140

141

142

143

144

145

146

147

148

149

150

151

152

153

\section{Vector construction and site-directed mutation}

To analyze the effect of TLR4 promoter region genetic variation on transcriptional activity, we constructed a reporter plasmid containing -1762 to +70 base pairs of human TLR 4 promoter. The primers used to amplify this fragment were 5'-GGGGTACCCCGGATTGGAAGTGCTTGGAG3' and 5'-CTAGCTAGCTAGAAGAAGAAAACGCCTGC-3', which contain Kpn I and Nhe I recognition site (underlined sequence) in forward primer and reverse primer, respectively (Figure 1A). The PCR product was then cloned into pGL3-basic reporter vector (Promega, Madison, USA). Based on the sequence results, we constructed pGL3-rs1927914A-containing plasmid. The template vectors (pGL3-rs1927914 A) were then used to obtain pGL3-rs1927914G-containg vector by site-specific mutagenesis reaction using site-specific mutation kit (TIANGEN, Beijing, China). All constructs were verified by direct sequencing.

\section{Cell culture, Transfection and luciferase assay}

Esophageal carcinoma cells (KYSE30) were kindly gifted from Dr. Y. Shimada in Hyogo College of Medicine (Japan). Cells were cultured in DMEM medium containing 10\% FBS (Gibco, Vienna, Austria) and 1\% penicillin and streptomycin. Cells were seeded at a density of 3 x $10^{5}$ cells/well in $24-w e l l$ plate to $70-80 \%$ confluence. Cells were co-transfected with different pGL3-Basic vectors and pRL-SV40 using Lipofectamine ${ }^{\mathrm{TM}} 2000$ (Invitrogen, Carlsbad, USA). Luciferase activity was detected by Dual Luciferase Reporter Assay. A $13 \mu \mathrm{L}$ of cell lysate was 
154

155

156

157

158

159

160

161

162

163

164

165

166

167

168

169

170

171

172

173

174

175

176

177

178

mixed with $25 \mu \mathrm{L}$ of Luciferase Assay Reagent II, and Firefly luciferase activity was measured by GloMax 20/20 Luminometer. Then, $25 \mu \mathrm{L}$ of $1 \times$ Stop \& Glo solution was added to determine Renilla luciferase activity. The ratio of Firefly and Renilla luciferase activity was presented to the level of relative luciferase activity. Independent experiments were performed three times.

\section{Electrophoretic mobility shift assay (EMSA)}

The biotin-labeled oligonucleotide probes (5'-TCTAGGACTTAGCATACAAATATTCCTGTT3' and 5'-TCTAGGACTTAGCATGCAAATATTCCTGTT-3') containing TLR4 rs1927914 A/G allele was synthesized by Sangon Biotech (Shanghai, China). Nuclear proteins were extracted from KYSE30 cells by using NE-PER ${ }^{\mathrm{TM}}$ Nuclear and Cytoplasmic Extraction Reagents (Thermo Fisher Scientific, Waltham, USA). The electrophoretic mobility shift assays were conducted by using the LightShift ${ }^{\mathrm{TM}}$ Chemiluminescent EMSA kit (Thermo Fisher Scientific, Waltham, USA) following the instruction from manufacturer. Briefly, each $20 \mathrm{fmol}$ labeled oligonucleotide was incubated with $8 \mu \mathrm{g}$ nuclear extract for $10 \mathrm{~min}$ in $1 \times$ binding solutions. For competition experiment, we added $4 \mathrm{pmol}$ unlabeled oligonucleotide probe before incubating with labeled probe. After electrophoresis in a $6.5 \%$ polyacrylamide gel, the electrophoresed binding reactions were transferred to positively charged nylon membrane and then were crosslinked by UVJLY-1 UV-light crosslinking instrument of JIAYUAN Industrial Technology (Beijing, China). Biotin-labeled DNA was then detected and visualized by Luminol/Enhancer Solution and Stable Peroxidase Solution in LightShift ${ }^{\mathrm{TM}}$ Chemiluminescent EMSA kit.

\section{Statistical analysis}

In this study, all the research data were statistically analyzed using SPSS 23.0 (SPSS, Chicago, USA). The differences of basic characteristics in cases and controls were tested by $\chi^{2}$ test. The Hardy-Weinberger equilibrium (HWE) of TLR4 polymorphisms in controls were tested by $\chi^{2}$ 
test. The correlation between the genetic variants in TLR4 and the risk of esophageal cancer were evaluated by $O R$ and $95 \% C I$. The activity of luciferase reporter gene was compared by two independent sample t-test. $P<0.05$ indicated statistically significant. Linkage disequilibrium (LD) analysis was performed by HaploReg (Ward \& Kellis 2012).

\section{Results}

\section{Study subjects' general demographic characteristics}

The general information of all subjects was showed in Table 1. There were no significant differences in age and gender between the cases and controls $(P>0.05)$. The proportion of smokers in the case group was $64.4 \%$ and in control group was $30.6 \%(P<0.001)$, indicating a statistical difference. However, there were no statistically significant differences in cumulative smoking among ESCC patients and healthy controls $(P=0.149)$.

\section{The influence of TLR4 variants on ESCC risk}

After predicted by TRANSFAC program and SNPinfo Web Server, three potential functional SNPs (rs1927914, rs7873784, rs1536891) were selected for further analysis (Table 2). After genotyping TLR4 rs7873784 polymorphism in 100 samples, we found that the frequencies of GG, GC and CC genotype were $87.0 \%, 12.0 \%$ and $10 \%$ which is the same as that of TT, CT and CC genotype of rs11536891 variant. We then measured the amount of linkage disequilibrium (LD) and demonstrated that two TLR4 SNPs (rs7873784 and rs11536891) conformed to complete genetic linkage with D' of 1.00 and $r^{2}$ of 1.00 . Based on this, in further study, we only genotyped TLR4 rs11536891 and rs1927914 polymorphisms. Table 3 showed the association of TLR4 rs1927914 and rs11536891 genotypes with the susceptibility to esophageal cancer. Genotypes distribution of 2 SNPs among controls group were consistent with the Hardy- 
203

204

205

206

207

208

209

210

211

212

213

214

215

216

217

218

219

220

221

222

223

224

225

226

227

Weinberg equilibrium (HWE), indicating that the selected population was well representative.

The genotypes frequencies of TLR4 rs 1927914 AA, GA and GG were 40.6\% (195), 49.4\% (237) and $10 \%(48)$ in cases and 35.2\% (169), 49.6\% (238) and 15.2\% (73) in controls. Multivariate logistic regression analysis displayed that rs1927914 GG genotype contributed to a decrease ESCC risk $(O R=0.59,95 \% C I=0.38-0.93, P=0.023)$ when compared with AA genotype.

There was no significant difference in the distribution of TLR4 rs11536891 genotypes in the case group and the control group $(P>0.05)$.

\section{Stratification analysis}

The stratification analysis by gender, age and smoking status was used to further explore the interaction effect of genetic variation of TLR4 rs1927914 on ESCC risk (Table 4). When stratified by gender, there was no significant correlation between genotypes of TLR4 rs 1927914 and the esophageal cancer risk among males and females $(O R=0.67,95 \% C I=0.41-1.09 ; O R=$ $0.31,95 \% C I=0.09-1.11)$. In the age stratification, median age (50-year) in controls was set as cut-off value for all subjects. Our data showed that older subjects (age $>50)$ with GG genotype had a lower esophageal cancer risk than those with the AA genotype $(O R=0.59,95 \% C I=0.36$ $0.97)$, but the younger subjects didn't $(O R=0.53,95 \% C I=0.18-1.55)$. In a stratified analysis based on smoking status, we found that the GG genotype was a protective factor among nonsmoker $(O R=0.36,95 \% C I=0.18-0.73)$, but not among smoker $(O R=0.93,95 \% C I=0.49$ 1.76).

\section{Luciferase reporter gene activity detection}

For further verification, we assessed the effect of TLR4 rs1927914 genetic variation on transcriptional activity. We transiently transfected the recombinant plasmid with rs1927914A (pGL3-Basic-A), G allele (pGL3-Basic-G) or pGL3-Basic into KYSE30 cells together with an 
228

229

230

231

232

233

234

235

236

237

238

239

240

241

242

243

244

245

246

247

248

249

250

251

252

253

internal control plasmid to detect the expression of luciferase activity, respectively. The results showed that luciferase activity drived by TLR4 rs1927914 G allele was 1.76-fold higher than that by rs 1927914 A allele $(P=0.0043)$ (Figure 1B).

\section{Allele-specific binding of nuclear proteins to TLR4 promoter}

We conducted the electrophoretic mobility shift assay to investigate if different TLR4 rs1927914 allele effected on the binding activity to transcriptional factor. Biotin-labeled probes containing two different alleles (rs1927914 A and G) were respectively reacted with the KYSE30 nuclear extract. As showed in Figure 1C, rs1927914G-protein complex was determined (lane 5), but rs 1927914A-protein complex wasn't (lane 2). This indicated the capability of rs1927914G allele, not rs 1927914A, to bind nuclear protein. This complex also can be inhibited by excess unlabeled oligonucleotide probe (lane 6).

\section{Discussion}

Because the symptoms of esophageal cancer are not obvious in the early stage, most of the patients are diagnosed in the middle and late stages and often accompanied by malnutrition. A multicenter study, which investigated the potential epidemiological and clinical risk factors affecting the survival of esophageal cancer patients in China, demonstrated that the overall 5year survival rate is around 39\% (He et al. 2020). Multiple large clinical studies have shown that concurrent chemoradiotherapy (CCRT) can significantly improve the local control rate and the overall survival rate of esophageal cancer (Kang et al. 2018; Takeda et al. 2018). Therefore, CCRT is still the standard therapy for patients with locally advanced esophageal cancer who cannot receive or refuse surgical treatment. However, CCRT is not tolerated in patients with advanced age, severe cardiopulmonary complications or malnutrition. In the past decade, targeted therapy has brought cancer treatment into the era of precision therapy with its low toxic side effects and high therapeutic efficiency. The discovery of EGFR, ALK and other driving 
254 genes in lung cancer provides an example for targeted therapy of malignant tumors. Therefore, it

255 is still necessary to look for potential molecular targets to guide the clinical treatment of 256 esophageal cancer.

257

258

259

260

261

262

263

264

265

266

267

268

269

270

271

272

273

274

275

276

277

278

279

TLRs are important components of inflammatory response by effecting on innate immune response. So far, 10 members (TLR1-TLR10) have been identified in TLR family which involved in multiple biological processes, such as inflammatory response, immune response, apoptosis and angiogenesis and further contributed to the development of various cancers (Belmont et al. 2014; Dajon et al. 2017; Garcia et al. 2016; Paone et al. 2010; Vijay 2018) TLR4 locates in chromosome 9q32-33. TLR4 mRNA can be polyadenylated at 3'UTR to produce 5432nt and 12853nt transcripts that both encode the same 839aa protein. Kutikhin et al. found that the high expression of TLR4 in cancer tissues can promote the metastasis and invasion of tumor cells, and it is not suppressed by the immune system (Davoodi et al. 2013; Kutikhin et al. 2014). The overexpression of TLR4 in ESCC tissues was also associated with the poor prognosis (Li et al. 2018; Sato et al. 2020).

So far, several studies have found that TLR4 polymorphisms influence cancer susceptibility, such as gastric cancer, myeloma and hepatocellular carcinoma (Bagratuni et al. 2016; He et al. 2018; Huang et al. 2017). In Chinese population, Huang et al. found that there is a significantly decreased risk of gastric cancer in individuals carrying of the allele $\mathrm{C}$ for the rs 10116253 and allele T for the rs1927911 in TLR4 (Huang et al. 2014). Similar results were found in hepatocellular carcinoma (Minmin et al. 2011). Song et al. found that both TLR4 rs 1927911 and rs11536858 polymorphism increased the susceptibility of prostate cancer in Korean Men (Song et al. 2009).

In this study, the online databases of TRANSFAC and SNPinfo Web Server were used to predict the SNPs that may affect the expression of TLR4. The prediction results showed that rs 1927914 in the promoter TLR4 affected the binding capability of the organic cation transporter 1 (Oct-1) which is a member of the POU homeodomain family of transcription factors (Verrijzer 
280

281

282

283

284

285

286

287

288

289

290

291

292

293

294

295

296

297

\& Van der Vliet 1993). The main feature of this family is its highly conserved original POU domain composed of 150 amino acids, which has a high affinity for the octamer binding sequence 5'-ATGCAAAT-3' (Verrijzer et al. 1992). Studies have showed that Oct-1 was abnormally expressed in a variety of cancers and the overexpression of Oct-1 was associated with the poor prognosis in well-differentiated gastric adenocarcinoma patients (Jeong et al. 2014; Rhodes et al. 2007). In this study, our results demonstrated that TLR4 rs 1927914 A $>$ G genetic polymorphism contributed to a reduced risk of esophageal cancer. This finding was further supported by luciferase reporter assay which showed that TLR4 rs1927914 G-containing constructure displayed higher luciferase activity than rs1927914A-containing constructure. We also found that the oligonucleotide probe with TLR4 rs1927914G could bind with the nuclear extract from esophageal cancer cells using EMSA; however, that with rs1927914A allele couldn't. There were several studies reported the association of rs1927914 polymorphism with the risk of other cancer types. For example, Shi and Minmin et al. reported that TLR4 rs1927914 genetic variations are correlated with the hepatocellular carcinoma susceptibility (Minmin et al. 2011; Shi et al. 2017). However, researchers didn't find the correlation between TLR4 rs 1927914 and the risk of lung or gastric cancer (Huang et al. 2010; Wu et al. 2020). Therefore, it is suggested that TLR4 rs1927914 may be associated with the occurrence of certain cancer type. For rs11536891 polymorphisms, we predicted that it affected the binding capability of hsamiR-519a/hsa-miR-519b-3p; however, our study didn't show this SNP on the risk of esophageal cancer. At present, there are few studies on the correlation between TLR4 rs11536891 polymorphism and cancer susceptibility. Researchers didn't find that TLR4 rs11536891 was associated with the risk of prostate cancer and lung cancer (Song et al. 2009; Wu et al. 2020). Tsilidis et al. reported that this SNP was contributed to the colorectal cancer risk (Tsilidis et al. 2009). These findings suggested that TLR4 might promote esophageal cancer cell proliferation through different pathways.

In addition to genetic factors, epidemiological evidence also proved that cigarette smoking strongly elevated the susceptibility to ESCC (Abnet et al. 2018; Chen et al. 2010; Dong \& Thrift 
307 2017). Thus, we performed stratification analysis by smoking status and found TLR4 rs 1927914

308 GG genotype carriers had decreased risk of ESCC among non-smokers, but not among smokers.

309 Meanwhile, we found that GG genotype is a protective factor for older subjects. These results

310 suggest that the risk of ESCC is mainly caused by the combination of environmental and genetic

311 factors.

312

313 Conclusion

In summary, we found that $\mathrm{rs} 1927914 \mathrm{~A}>\mathrm{G}$ polymorphism in the promoter of TLR4 could

315 affect the transcriptional activity of TLR4 and contributed to the susceptibility to ESCC. These

316 data further supported the hypothesis that naturally occurring variants in innate immune genes

317 conferred individual's susceptibility to esophageal cancer. The TLR4 polymorphism might serve

318 as a biomarker for evaluation of lung cancer risk.

\section{Acknowledgments}

The authors thank all patients and control subjects for their participation.

Data Availability

The following information was supplied regarding data availability:

The raw data are available as a Supplementary File.

\section{References}


329

330

331

332

333

334

335

336

337

338

339

340

341

342

343

344

345

346

347

348

349

350

351

352

Abnet CC, Arnold M, and Wei WQ. 2018. Epidemiology of Esophageal Squamous Cell Carcinoma. Gastroenterology 154:360-373. 10.1053/j.gastro.2017.08.023

Bagratuni T, Terpos E, Eleutherakis-Papaiakovou E, Kalapanida D, Gavriatopoulou M, Migkou M, Liacos CI, Tasidou A, Matsouka C, Mparmparousi D, Dimopoulos MA, and Kastritis E. 2016. TLR4/TIRAP polymorphisms are associated with progression and survival of patients with symptomatic myeloma. Br J Haematol 172:44-47. 10.1111/bjh.13786

Belmont L, Rabbe N, Antoine M, Cathelin D, Guignabert C, Kurie J, Cadranel J, and Wislez M. 2014. Expression of TLR9 in tumor-infiltrating mononuclear cells enhances angiogenesis and is associated with a worse survival in lung cancer. Int J Cancer 134:765-777. $10.1002 / \mathrm{ijc} .28413$

Bray F, Ferlay J, Soerjomataram I, Siegel RL, Torre LA, and Jemal A. 2018. Global cancer statistics 2018: GLOBOCAN estimates of incidence and mortality worldwide for 36 cancers in 185 countries. CA Cancer J Clin 68:394-424. 10.3322/caac.21492

Chen J, Zhang N, Wakai T, Wei L, He Y, Kumagai N, Kitsu K, Wang S, and Akazawa K. 2010. Effect of the interaction between the amount and duration of alcohol consumption and tobacco smoking on the risk of esophageal cancer: A case-control study. Exp Ther Med 1:991-997. 10.3892/etm.2010.152

Dajon M, Iribarren K, and Cremer I. 2017. Toll-like receptor stimulation in cancer: A pro- and anti-tumor double-edged sword. Immunobiology 222:89-100. 10.1016/j.imbio.2016.06.009

Davoodi H, Hashemi SR, and Seow HF. 2013. 5-Fluorouracil Induce the Expression of TLR4 on HCT116 Colorectal Cancer Cell Line Expressing Different Variants of TLR4. Iran J Pharm Res 12:453-460.

de Visser KE, Eichten A, and Coussens LM. 2006. Paradoxical roles of the immune system 
354

355

356

357

358

359

360

361

362

363

364

365

366

367

Domper Arnal MJ, Ferrández Arenas Á, and Lanas Arbeloa Á. 2015. Esophageal cancer: Risk factors, screening and endoscopic treatment in Western and Eastern countries. World $J$ Gastroenterol 21:7933-7943. 10.3748/wjg.v21.i26.7933

Dong J, and Thrift AP. 2017. Alcohol, smoking and risk of oesophago-gastric cancer. Best Pract Res Clin Gastroenterol 31:509-517. 10.1016/j.bpg.2017.09.002

Fang H, Ang B, Xu X, Huang X, Wu Y, Sun Y, Wang W, Li N, Cao X, and Wan T. 2014. TLR4 is essential for dendritic cell activation and anti-tumor T-cell response enhancement by DAMPs released from chemically stressed cancer cells. Cell Mol Immunol 11:150-159. $10.1038 / \mathrm{cmi} .2013 .59$

Garcia PV, Seiva FR, Carniato AP, de Mello Júnior W, Duran N, Macedo AM, de Oliveira AG, Romih R, Nunes Ida S, Nunes Oda S, and Fávaro WJ. 2016. Increased toll-like receptors and p53 levels regulate apoptosis and angiogenesis in non-muscle invasive bladder cancer: mechanism of action of P-MAPA biological response modifier. BMC Cancer $16: 422.10 .1186 / \mathrm{s} 12885-016-2474-\mathrm{z}$

Guo Y, Zhang X, Tan W, Miao X, Sun T, Zhao D, and Lin D. 2007. Platelet 12-lipoxygenase Arg261Gln polymorphism: functional characterization and association with risk of esophageal squamous cell carcinoma in combination with COX-2 polymorphisms. Pharmacogenet Genomics 17:197-205. 10.1097/FPC.0b013e328010bda1

He B, Xu T, Pan B, Pan Y, Wang X, Dong J, Sun H, Xu X, Liu X, and Wang S. 2018. Polymorphisms of TGFBR1, TLR4 are associated with prognosis of gastric cancer in a Chinese population. Cancer Cell Int 18:191. 10.1186/s12935-018-0682-0

He W, Liu Q, Wang L, Chen W, Li N, and Cao X. 2007. TLR4 signaling promotes immune escape of human lung cancer cells by inducing immunosuppressive cytokines and 
apoptosis resistance. Mol Immunol 44:2850-2859. 10.1016/j.molimm.2007.01.022

378

379

380

381

382

383

384

385

386

387

388

389

390

391

392

393

394

395

396

397

398

399

400

He Y, Liang D, Du L, Guo T, Liu Y, Sun X, Wang N, Zhang M, Wei K, Shan B, and Chen W. 2020. Clinical characteristics and survival of 5283 esophageal cancer patients: A multicenter study from eighteen hospitals across six regions in China. Cancer Commun (Lond) 40:531-544. 10.1002/cac2.12087

Hiyama T, Yoshihara M, Tanaka S, and Chayama K. 2007. Genetic polymorphisms and esophageal cancer risk. Int J Cancer 121:1643-1658. 10.1002/ijc.23044

Huang C, Zhang H, Bai R, Wang L, and Lv J. 2017. A896G and C1196T Polymorphisms Within the TLR4 Gene Abate Toll-Like Receptor 4-Mediated Signaling in HepG2 Cells. DNA Cell Biol 36:1029-1038. 10.1089/dna.2017.3892

Huang H, Wu J, Jin G, Zhang H, Ding Y, Hua Z, Zhou Y, Xue Y, Lu Y, Hu Z, Xu Y, and Shen H. 2010. A 5'-flanking region polymorphism in toll-like receptor 4 is associated with gastric cancer in a Chinese population. J Biomed Res 24:100-106. 10.1016/s1674$8301(10) 60017-6$

Huang L, Yuan K, Liu J, Ren X, Dong X, Tian W, and Jia Y. 2014. Polymorphisms of the TLR4 gene and risk of gastric cancer. Gene 537:46-50. 10.1016/j.gene.2013.12.030

Jacobsen N, Aasenden R, and Hensten-Pettersen A. 1991. Occupational health complaints and adverse patient reactions as perceived by personnel in public dentistry. Community Dent Oral Epidemiol 19:155-159. 10.1111/j.1600-0528.1991.tb00132.x

Jeong SH, Lee YJ, Cho BI, Ha WS, Choi SK, Jung EJ, Ju YT, Jeong CY, Ko GH, Yoo J, and Hong SC. 2014. OCT-1 overexpression is associated with poor prognosis in patients with well-differentiated gastric cancer. Tumour Biol 35:5501-5509. 10.1007/s13277-014$1724-4$

Kaczanowska S, Joseph AM, and Davila E. 2013. TLR agonists: our best frenemy in cancer 
402

403

404

405

406

407

408

409

410

411

412

413

414

415

416

417

Kang J, Chang JY, Sun X, Men Y, Zeng H, and Hui Z. 2018. Role of Postoperative Concurrent Chemoradiotherapy for Esophageal Carcinoma: A meta-analysis of 2165 Patients. $J$ Cancer 9:584-593. 10.7150/jca.20940

Kutikhin AG, Yuzhalin AE, Volkov AN, Zhivotovskiy AS, and Brusina EB. 2014. Correlation between genetic polymorphisms within IL-1B and TLR4 genes and cancer risk in a Russian population: a case-control study. Tumour Biol 35:4821-4830. 10.1007/s13277014-1633-6

Li J, Yin J, Shen W, Gao R, Liu Y, Chen Y, Li X, Liu C, Xiang R, and Luo N. 2017. TLR4 Promotes Breast Cancer Metastasis via Akt/GSK3 $\beta / \beta$-Catenin Pathway upon LPS Stimulation. Anat Rec (Hoboken) 300:1219-1229. 10.1002/ar.23590

Li X, Li H, Dong X, Wang X, Zhu J, Cheng Y, and Fan P. 2018. Expression of NF- $\kappa$ B and TLR4 is associated with the occurrence, progression and prognosis of esophageal squamous cell carcinoma. Int J Clin Exp Pathol 11:5850-5859.

Lin Y, Totsuka Y, He Y, Kikuchi S, Qiao Y, Ueda J, Wei W, Inoue M, and Tanaka H. 2013. Epidemiology of esophageal cancer in Japan and China. J Epidemiol 23:233-242. 10.2188/jea.je20120162

Minmin S, Xiaoqian X, Hao C, Baiyong S, Xiaxing D, Junjie X, Xi Z, Jianquan Z, and Songyao J. 2011. Single nucleotide polymorphisms of Toll-like receptor 4 decrease the risk of development of hepatocellular carcinoma. PLoS One 6:e19466. 10.1371/journal.pone.0019466

Pandey N, Chauhan A, and Jain N. 2018. TLR4 Polymorphisms and Expression in Solid Cancers. Mol Diagn Ther 22:683-702. 10.1007/s40291-018-0361-9

Paone A, Galli R, Gabellini C, Lukashev D, Starace D, Gorlach A, De Cesaris P, Ziparo E, Del 
425

426

427

428

429

430

431

432

433

434

435

436

437

438

439

440

441

442

443

444

445

446

447

448

Bufalo D, Sitkovsky MV, Filippini A, and Riccioli A. 2010. Toll-like receptor 3 regulates angiogenesis and apoptosis in prostate cancer cell lines through hypoxia-inducible factor 1 alpha. Neoplasia 12:539-549. 10.1593/neo.92106

Pham TN, Hong CY, Min JJ, Rhee JH, Nguyen TA, Park BC, Yang DH, Park YK, Kim HR, Chung IJ, Kim HJ, and Lee JJ. 2010. Enhancement of antitumor effect using dendritic cells activated with natural killer cells in the presence of Toll-like receptor agonist. Exp Mol Med 42:407-419. 10.3858/emm.2010.42.6.042

Rhodes DR, Kalyana-Sundaram S, Mahavisno V, Varambally R, Yu J, Briggs BB, Barrette TR, Anstet MJ, Kincead-Beal C, Kulkarni P, Varambally S, Ghosh D, and Chinnaiyan AM. 2007. Oncomine 3.0: genes, pathways, and networks in a collection of 18,000 cancer gene expression profiles. Neoplasia 9:166-180. 10.1593/neo.07112

Rocha DM, Caldas AP, Oliveira LL, Bressan J, and Hermsdorff HH. 2016. Saturated fatty acids trigger TLR4-mediated inflammatory response. Atherosclerosis 244:211-215. 10.1016/j.atherosclerosis.2015.11.015

Sato Y, Motoyama S, Wakita A, Kawakita Y, Liu J, Nagaki Y, Nanjo H, Ito S, Terata K, Imai K, and Minamiya Y. 2020. High TLR4 expression predicts a poor prognosis after esophagectomy for advanced thoracic esophageal squamous cell carcinoma. Esophagus 17:408-416. 10.1007/s10388-020-00732-x

Schreiber RD, Old LJ, and Smyth MJ. 2011. Cancer immunoediting: integrating immunity's roles in cancer suppression and promotion. Science 331:1565-1570. 10.1126/science. 1203486

Shetab Boushehri MA, and Lamprecht A. 2018. TLR4-Based Immunotherapeutics in Cancer: A Review of the Achievements and Shortcomings. Mol Pharm 15:4777-4800. 10.1021/acs.molpharmaceut.8b00691 
449

450

451

452

453

454

455

456

457

458

459

460

461

462

463

464

465

466

467

468

469

470

471

472

Sheyhidin I, Nabi G, Hasim A, Zhang RP, Ainiwaer J, Ma H, and Wang H. 2011. Overexpression of TLR3, TLR4, TLR7 and TLR9 in esophageal squamous cell carcinoma. World J Gastroenterol 17:3745-3751. 10.3748/wjg.v17.i32.3745

Shi G, Wang C, Zhang P, Ji L, Xu S, Tan X, and Li H. 2017. Donor Polymorphisms of Toll-like Receptor 4 rs1927914 Associated with the Risk of Hepatocellular Carcinoma Recurrence Following Liver Transplantation. Arch Med Res 48:553-560. 10.1016/j.arcmed.2017.11.011

Song J, Kim DY, Kim CS, Kim HJ, Lee DH, Lee HM, Ko W, and Lee G. 2009. The association between Toll-like receptor 4 (TLR4) polymorphisms and the risk of prostate cancer in Korean men. Cancer Genet Cytogenet 190:88-92. 10.1016/j.cancergencyto.2008.12.011

Takeda K, Umezawa R, Takahashi N, Matsushita H, Kozumi M, Ishikawa Y, Yamamoto T, Takeda K, and Jingu K. 2018. Impact of change in serum albumin level during and after chemoradiotherapy in patients with locally advanced esophageal cancer. Esophagus 15:190-197. 10.1007/s10388-018-0612-1

Terme M, and Tanchot C. 2017. [Immune system and tumors]. Ann Pathol 37:11-17. 10.1016/j.annpat.2016.12.004

Tsilidis KK, Helzlsouer KJ, Smith MW, Grinberg V, Hoffman-Bolton J, Clipp SL, Visvanathan K, and Platz EA. 2009. Association of common polymorphisms in IL10, and in other genes related to inflammatory response and obesity with colorectal cancer. Cancer Causes Control 20:1739-1751. 10.1007/s10552-009-9427-7

Verrijzer CP, Alkema MJ, van Weperen WW, Van Leeuwen HC, Strating MJ, and van der Vliet PC. 1992. The DNA binding specificity of the bipartite POU domain and its subdomains. Embo j 11:4993-5003.

Verrijzer CP, and Van der Vliet PC. 1993. POU domain transcription factors. Biochim Biophys 
474

475

476

477

478

479

480

481

482

483

484

485

486

487

488

489

490

491

492

493

494

495

496

Vijay K. 2018. Toll-like receptors in immunity and inflammatory diseases: Past, present, and future. Int Immunopharmacol 59:391-412. 10.1016/j.intimp.2018.03.002

Wang K, Wang J, Wei F, Zhao N, Yang F, and Ren X. 2017. Expression of TLR4 in Non-Small Cell Lung Cancer Is Associated with PD-L1 and Poor Prognosis in Patients Receiving Pulmonectomy. Front Immunol 8:456. 10.3389/fimmu.2017.00456

Ward LD, and Kellis M. 2012. HaploReg: a resource for exploring chromatin states, conservation, and regulatory motif alterations within sets of genetically linked variants. Nucleic Acids Res 40:D930-934. 10.1093/nar/gkr917

Wingender E, Dietze P, Karas H, and Knüppel R. 1996. TRANSFAC: a database on transcription factors and their DNA binding sites. Nucleic Acids Res 24:238-241. $10.1093 /$ nar/24.1.238

Wu C, Li D, Jia W, Hu Z, Zhou Y, Yu D, Tong T, Wang M, Lin D, Qiao Y, Zhou Y, Chang J, Zhai K, Wang M, Wei L, Tan W, Shen H, Zeng Y, and Lin D. 2013. Genome-wide association study identifies common variants in SLC39A6 associated with length of survival in esophageal squamous-cell carcinoma. Nat Genet 45:632-638. 10.1038/ng.2638

Wu H, Gao H, Li A, Xie Y, Jia Z, Yang Z, Zhang H, Zhang Z, and Zhang X. 2020. Impact of Genetic Variation in TLR4 3'UTR on NSCLC Genetic Susceptibility. J Oncol 2020:7593143. 10.1155/2020/7593143

$\mathrm{Xu}$ Z, and Taylor JA. 2009. SNPinfo: integrating GWAS and candidate gene information into functional SNP selection for genetic association studies. Nucleic Acids Res 37:W600-605. 10.1093/nar/gkp290

Yang CS, Chen X, and Tu S. 2016. Etiology and Prevention of Esophageal Cancer. Gastrointest 
Yu C, Tang H, Guo Y, Bian Z, Yang L, Chen Y, Tang A, Zhou X, Yang X, Chen J, Chen Z, Lv J, and Li L. 2018a. Hot Tea Consumption and Its Interactions With Alcohol and Tobacco Use on the Risk for Esophageal Cancer: A Population-Based Cohort Study. Ann Intern Med 168:489-497. 10.7326/m17-2000

Yu H, Yan H, Wang L, Li J, Tan L, Deng W, Chen Q, Yang G, Zhang F, Lu T, Yang J, Li K, Lv L, Tan Q, Zhang H, Xiao X, Li M, Ma X, Yang F, Li L, Wang C, Li T, Zhang D, and Yue W. 2018b. Five novel loci associated with antipsychotic treatment response in patients with schizophrenia: a genome-wide association study. Lancet Psychiatry 5:327338. $10.1016 / \mathrm{s} 2215-0366(18) 30049-\mathrm{x}$

Yue C, Li M, Da C, Meng H, Lv S, and Zhao X. 2017. Association between genetic variants and esophageal cancer risk. Oncotarget 8:47167-47174. 10.18632/oncotarget.17006

Zhang H, Ahearn TU, Lecarpentier J, Barnes D, Beesley J, Qi G, Jiang X, O'Mara TA, Zhao N, Bolla MK, Dunning AM, Dennis J, Wang Q, Ful ZA, Aittomäki K, Andrulis IL, AntonCulver H, Arndt V, Aronson KJ, Arun BK, Auer PL, Azzollini J, Barrowdale D, Becher H, Beckmann MW, Behrens S, Benitez J, Bermisheva M, Bialkowska K, Blanco A, Blomqvist C, Bogdanova NV, Bojesen SE, Bonanni B, Bondavalli D, Borg A, Brauch H, Brenner H, Briceno I, Broeks A, Brucker SY, Brüning T, Burwinkel B, Buys SS, Byers H, Caldés T, Caligo MA, Calvello M, Campa D, Castelao JE, Chang-Claude J, Chanock SJ, Christiaens M, Christiansen H, Chung WK, Claes KBM, Clarke CL, Cornelissen S, Couch FJ, Cox A, Cross SS, Czene K, Daly MB, Devilee P, Diez O, Domchek SM, Dörk T, Dwek M, Eccles DM, Ekici AB, Evans DG, Fasching PA, Figueroa J, Foretova L, Fostira F, Friedman E, Frost D, Gago-Dominguez M, Gapstur SM, Garber J, GarcíaSáenz JA, Gaudet MM, Gayther SA, Giles GG, Godwin AK, Goldberg MS, Goldgar DE, González-Neira A, Greene MH, Gronwald J, Guénel P, Häberle L, Hahnen E, Haiman CA, Hake CR, Hall P, Hamann U, Harkness EF, Heemskerk-Gerritsen BAM, Hillemanns 
P, Hogervorst FBL, Holleczek B, Hollestelle A, Hooning MJ, Hoover RN, Hopper JL, Howell A, Huebner H, Hulick PJ, Imyanitov EN, Isaacs C, Izatt L, Jager A, Jakimovska M, Jakubowska A, James P, Janavicius R, Janni W, John EM, Jones ME, Jung A, Kaaks R, Kapoor PM, Karlan BY, Keeman R, Khan S, Khusnutdinova E, Kitahara CM, Ko YD, Konstantopoulou I, Koppert LB, Koutros S, Kristensen VN, Laenkholm AV, Lambrechts D, Larsson SC, Laurent-Puig P, Lazaro C, Lazarova E, Lejbkowicz F, Leslie G, Lesueur F, Lindblom A, Lissowska J, Lo WY, Loud JT, Lubinski J, Lukomska A, MacInnis RJ,

Mannermaa A, Manoochehri M, Manoukian S, Margolin S, Martinez ME, Matricardi L, McGuffog L, McLean C, Mebirouk N, Meindl A, Menon U, Miller A, Mingazheva E, Montagna M, Mulligan AM, Mulot C, Muranen TA, Nathanson KL, Neuhausen SL, Nevanlinna H, Neven P, Newman WG, Nielsen FC, Nikitina-Zake L, Nodora J, Offit K, Olah E, Olopade OI, Olsson H, Orr N, Papi L, Papp J, Park-Simon TW, Parsons MT, Peissel B, Peixoto A, Peshkin B, Peterlongo P, Peto J, Phillips KA, Piedmonte M, Plaseska-Karanfilska D, Prajzendanc K, Prentice R, Prokofyeva D, Rack B, Radice P, Ramus SJ, Rantala J, Rashid MU, Rennert G, Rennert HS, Risch HA, Romero A, Rookus MA, Rübner M, Rüdiger T, Saloustros E, Sampson S, Sandler DP, Sawyer EJ, Scheuner MT, Schmutzler RK, Schneeweiss A, Schoemaker MJ, Schöttker B, Schürmann P, Senter L, Sharma P, Sherman ME, Shu XO, Singer CF, Smichkoska S, Soucy P, Southey MC, Spinelli JJ, Stone J, Stoppa-Lyonnet D, Swerdlow AJ, Szabo CI, Tamimi RM, Tapper WJ, Taylor JA, Teixeira MR, Terry M, Thomassen M, Thull DL, Tischkowitz M, Toland AE, Tollenaar R, Tomlinson I, Torres D, Troester MA, Truong T, Tung N, Untch M, Vachon CM, van den Ouweland AMW, van der Kolk LE, van Veen EM, vanRensburg EJ, Vega A, Wappenschmidt B, Weinberg CR, Weitzel JN, Wildiers H, Winqvist R, Wolk A, Yang XR, Yannoukakos D, Zheng W, Zorn KK, Milne RL, Kraft P, Simard J, Pharoah PDP, Michailidou K, Antoniou AC, Schmidt MK, Chenevix-Trench G, Easton DF, Chatterjee N, and García-Closas M. 2020. Genome-wide association study identifies 32 novel breast cancer susceptibility loci from overall and subtype-specific analyses. Nat 
550

551

552

553

554

555

556

557

558

559

560

561

562

563

564

565

566

567

568

569

570

571

572

573

Genet 52:572-581. 10.1038/s41588-020-0609-2

Zhang X, Miao X, Tan W, Ning B, Liu Z, Hong Y, Song W, Guo Y, Zhang X, Shen Y, Qiang B, Kadlubar FF, and Lin D. 2005. Identification of functional genetic variants in cyclooxygenase-2 and their association with risk of esophageal cancer. Gastroenterology 129:565-576. 10.1016/j.gastro.2005.05.003

Zhao S, Sun M, Meng H, Ji H, Liu Y, Zhang M, Li H, Li P, Zhang Y, and Zhang Q. 2019. TLR4 expression correlated with PD-L1 expression indicates a poor prognosis in patients with peripheral T-cell lymphomas. Cancer Manag Res 11:4743-4756. 10.2147/cmar.S203156

Zheng L, Dai H, Zhou M, Li M, Singh P, Qiu J, Tsark W, Huang Q, Kernstine K, Zhang X, Lin D, and Shen B. 2007. Fen1 mutations result in autoimmunity, chronic inflammation and cancers. Nat Med 13:812-819. 10.1038/nm1599

Zu Y, Ping W, Deng T, Zhang N, Fu X, and Sun W. 2017. Lipopolysaccharide-induced toll-like receptor 4 signaling in esophageal squamous cell carcinoma promotes tumor proliferation and regulates inflammatory cytokines expression. Dis Esophagus 30:1-8. $10.1111 /$ dote. 12466

Figure legend

Figure 1. TLR4 locus with SNPs and the functional analysis of rs1927914. A. A schematic showing TLR4 locus with candidate SNPs. B. Luciferase expression of two constructers (pGL3rs1927914G and pGL3-rs1927914A) in KYSE30 cells co-transfected with pRL-SV40 to standardize the transfection efficiency. Luciferase levels of pGL3-Basic and pRL-SV40 were determined in triplicate. Fold increase was measured by defining the activity of the empty pGL-3 Basic vector as $1 .{ }^{*} P<0.05$. C. Electrophoretic mobility shift assays with biotin-labeled oligonucleotide probes containing TLR4 rs1927914A or G allele. Lanes 1 and 4 show the gel 
574 mobilities of the labeled probes without nuclear extracts; lanes 2 and 5 show the mobilities of the 575 labeled probes with nuclear extracts in the absence of competitor; and lanes 3 and 6 show the 576 mobilities of the labeled probes with nuclear extracts and unlabeled competitors. The arrow 577 localizes the major probe-nuclear protein complex. 


\section{Table $\mathbf{1}$ (on next page)}

Distributions of select characteristics in cases and control subjects 
1

Table 1 Distributions of select characteristics in cases and control subjects

\begin{tabular}{|c|c|c|c|c|c|c|}
\hline \multirow{2}{*}{ Variables } & \multicolumn{2}{|c|}{ case $(n=480)$} & \multirow[b]{2}{*}{$\square$} & \multicolumn{2}{|c|}{ Controls $(n=480)$} & \multirow{2}{*}{$\begin{array}{l}P \text { value }^{\mathrm{a}} \\
\square\end{array}$} \\
\hline & No & $(\%)$ & & No & $(\%)$ & \\
\hline Sex & & & & & & 0.930 \\
\hline Male & 403 & 84.0 & & 402 & 83.7 & \\
\hline Female & 77 & 16.0 & & 78 & 16.3 & \\
\hline Age & & & & & & 0.162 \\
\hline$\leq 50$ & 83 & 17.3 & & 100 & 20.8 & \\
\hline$>50$ & 397 & 82.7 & & 380 & 79.2 & \\
\hline Smoking status & & & & & & $<0.001$ \\
\hline Non-smoker & 171 & 35.6 & & 333 & 69.4 & \\
\hline Smoker & 309 & 64.4 & & 147 & 30.6 & \\
\hline \multicolumn{7}{|c|}{ Pack year of smoking ${ }^{b}$} \\
\hline$\leq 25$ & 123 & 39.8 & & 69 & 46.9 & 0.149 \\
\hline$>25$ & 186 & 60.2 & $\square$ & 78 & 53.1 & \\
\hline
\end{tabular}

3

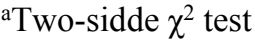

4

5

6 


\section{Figure 1}

TLR4 locus with SNPs and the functional analysis of rs1927914

A. A schematic showing TLR4 locus with candidate SNPs. B. Luciferase expression of two constructers ( $p$ GL3-rs1927914G and pGL3-rs1927914A) in KYSE30 cells co-transfected with pRL-SV40 to standardize the transfection efficiency. Luciferase levels of pGL3-Basic and pRLSV40 were determined in triplicate. Fold increase was measured by defining the activity of the empty pGL-3 Basic vector as $1 .{ }^{*} P<0.05$. C. Electrophoretic mobility shift assays with biotin-labeled oligonucleotide probes containing TLR4 rs1927914A or G allele. Lanes 1 and 4 show the gel mobilities of the labeled probes without nuclear extracts; lanes 2 and 5 show the mobilities of the labeled probes with nuclear extracts in the absence of competitor; and lanes 3 and 6 show the mobilities of the labeled probes with nuclear extracts and unlabeled competitors. The arrow localizes the major probe-nuclear protein complex. 
A

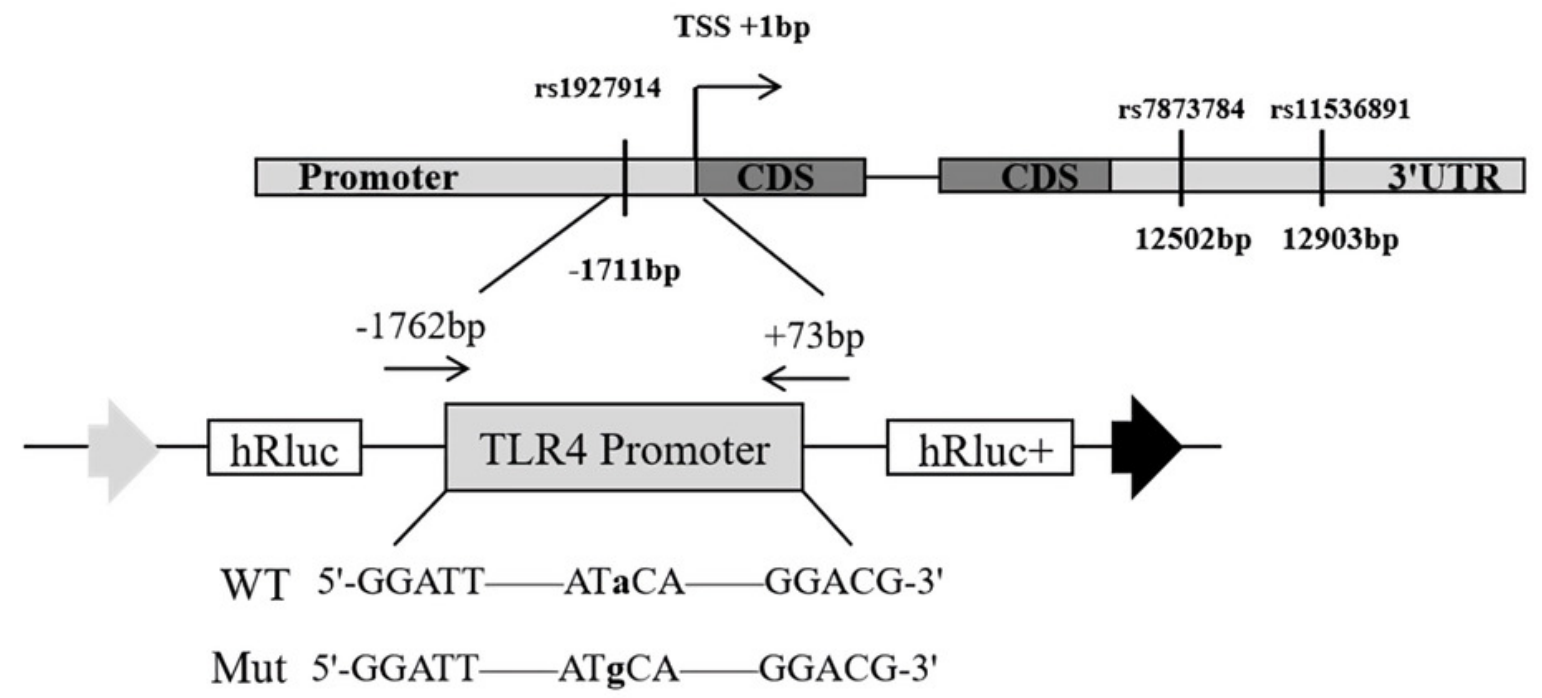

B

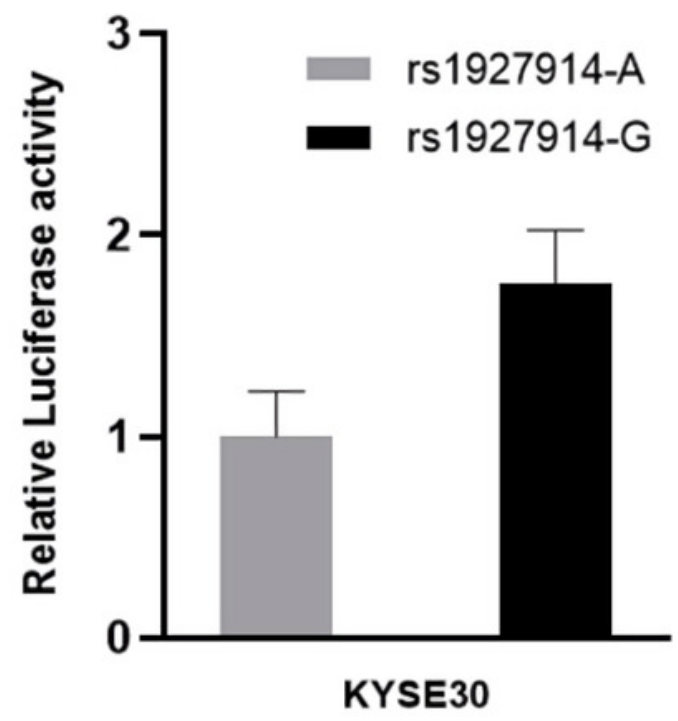

C

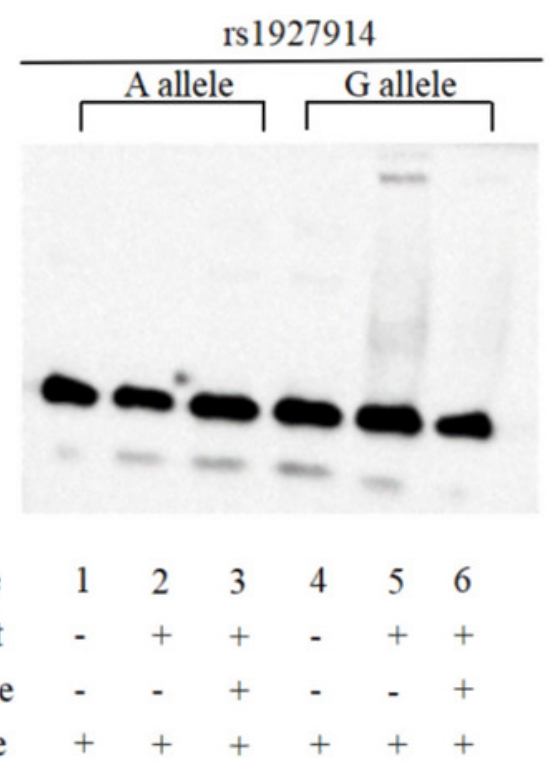


Table 2 (on next page)

General information of 3 SNPs of TLR4 
1

2

Table 2 General information of 3 SNPs of TLR4

\begin{tabular}{ccccc}
\hline SNP & Location & Allele & MAF & Functional changes \\
\hline rs1927914 & promoter region & A/G & 0.49 & Oct-1 \\
rs7873784 & 3'UTR & G/C & 0.14 & hsa-miR-144 \\
rs11536891 & 3'UTR & T/C & 0.14 & hsa-miR-519a, hsa-miR-519b-3p \\
\hline
\end{tabular}

3 
Table 3 (on next page)

Gene polymorphism of TLR4 and their association with ESCC 
1

Table 3 Gene polymorphism of TLR4 and their association with ESCC

\begin{tabular}{|c|c|c|c|c|c|c|c|}
\hline \multirow{2}{*}{ TLR4 genotypes } & \multicolumn{2}{|c|}{ Cases $(n=480)$} & \multirow{2}{*}{$\begin{array}{l}\square \\
\square\end{array}$} & \multicolumn{2}{|c|}{ Controls $(\mathrm{n}=480)$} & \multirow{2}{*}{$\begin{array}{l}\text { OR }(95 \% \mathrm{CI}) \\
\square\end{array}$} & \multirow{2}{*}{$\begin{array}{l}P \text { value }^{\mathrm{a}} \\
\square\end{array}$} \\
\hline & No & $(\%)$ & & No & $(\%)$ & & \\
\hline \multicolumn{8}{|l|}{ Rs1927914 } \\
\hline AA & 195 & 40.6 & & 169 & 35.2 & & \\
\hline GA & 237 & 49.4 & & 238 & 49.6 & $0.91(0.68-1.22)$ & 0.528 \\
\hline GG & 48 & 10.0 & $\square$ & 73 & 15.2 & $0.59(0.38-0.93)$ & 0.023 \\
\hline \multicolumn{8}{|l|}{ Rs11536891 } \\
\hline TT & 410 & 85.4 & & 410 & 85.4 & & \\
\hline $\mathrm{CT}$ & 64 & 13.3 & & 68 & 14.2 & $0.96(0.65-1.43)$ & 0.847 \\
\hline $\mathrm{CC}$ & 6 & 1.3 & & 2 & 0.4 & $4.59(0.87-24.25)$ & 0.073 \\
\hline
\end{tabular}

3 aData were analyzed by unconditional logistic regression and adjusted for sex, age and smoking status

4

5 
Table 4 (on next page)

Stratified analysis between TLR4 rs1927914 genotypes and ESCC risk 
Table 4 Stratified analysis between TLR4 rs1927914 genotypes and ESCC risk.

\begin{tabular}{|c|c|c|c|c|c|}
\hline \multirow{2}{*}{ Variables } & \multicolumn{3}{|c|}{ Genotypes (Cases/Controls) } & \multirow{2}{*}{$\begin{array}{l}\text { GG/AA model } \\
\text { OR }(95 \% \mathrm{CI})^{\mathrm{a}}\end{array}$} & \multirow{2}{*}{$\begin{array}{l}\text { GA/AA model } \\
\text { OR }(95 \% \mathrm{CI})^{\mathrm{a}}\end{array}$} \\
\hline & AA & GA & GG & & \\
\hline \multicolumn{6}{|l|}{ Sex } \\
\hline Male & $195 / 142$ & $237 / 197$ & $48 / 63$ & $0.67(0.41-1.09)$ & $0.95(0.69-1.32)$ \\
\hline Female & $35 / 27$ & $38 / 41$ & $4 / 10$ & $0.31(0.09-1.11)$ & $0.73(0.37-1.44)$ \\
\hline \multicolumn{6}{|l|}{ Age } \\
\hline$\leq 50$ & $38 / 33$ & $34 / 52$ & $11 / 15$ & $0.53(0.18-1.55)$ & $0.55(0.26-1.17)$ \\
\hline$>50$ & $157 / 136$ & $203 / 186$ & $37 / 58$ & $0.59(0.36-0.97)^{*}$ & $1.00(0.73-1.38)$ \\
\hline \multicolumn{6}{|l|}{ Smoking status } \\
\hline Non-smoker & $73 / 109$ & $86 / 170$ & $12 / 54$ & $0.36(0.18-0.73)^{*}$ & $0.76(0.51-1.13)$ \\
\hline Smoker & $122 / 60$ & $151 / 68$ & $36 / 19$ & $0.93(0.49-1.76)$ & $1.12(0.73-1.71)$ \\
\hline \multicolumn{6}{|c|}{ Pack year of smoking } \\
\hline$\leq 25$ & $49 / 28$ & $61 / 35$ & $13 / 6$ & $1.26(0.43-3.68)$ & $0.98(0.53-1.84)$ \\
\hline$>25$ & $73 / 32$ & $90 / 33$ & $23 / 13$ & $0.78(0.35-1.74)$ & $1.26(0.70-2.26)$ \\
\hline
\end{tabular}

3 aData were analyzed by unconditional logistic regression and adjusted for sex, age and smoking status

$4 \quad{ }^{*} P<0.05$

5 